\title{
A new pyrrolosesquiterpene isolated from cultures of Streptomyces sp.
}

\author{
Dong-Ze Liu ${ }^{1}$ and Bo-Wen Liang ${ }^{2}$ \\ One new pyrrolosesquiterpene 1 was isolated from the cultures of the soil actinomycete Streptomyces sp. Hd7-21. Its structure \\ was elucidated by extensive spectroscopic analyses including MS and one-dimensional and two-dimensional NMR data. \\ Compound 1 showed moderate cytotoxic activity against a panel of human cancer cell lines.
}

The Journal of Antibiotics (2014) 67, 415-417; doi:10.1038/ja.2014.8; published online 19 February 2014

Keywords: actinomycetes; cultures; pyrrolosesquiterpene

\section{INTRODUCTION}

Natural products are excellent sources of lead compounds to develop new drugs for the treatment of diseases. ${ }^{1}$ This is particularly evident in the treatment of cancers, in which more than $60 \%$ of the drugs are of natural origin. ${ }^{2}$ Hence, newly identified natural compounds with anticancer activity could represent a new tool for cancer therapy. Actinomycetes are widely distributed in nature, and are typically useful in the pharmaceutical industry for their seemingly unlimited capacity to produce secondary metabolites with diverse chemical structures and biological activities. ${ }^{3}$

Pyrroles have been incorporated into a variety of natural products, yet their appearance among terpenes is rare. To our knowledge, the only previously described pyrroloterpene natural products are pyrrolostatin ${ }^{4}$ and glyciapyrroles A-C. ${ }^{5}$ As part of our ongoing search for biologically active secondary metabolites, ${ }^{6-9}$ streptomyces sp. Hd7-21 from the soil sample collected in DaXingAnling virgin forest came to our attention as it displayed an interesting chemical profile from our initial LC-MS analysis. This prompted us to investigate the chemical diversity of this strain which led to the isolation of one new pyrrolosesquiterpene 1 . We herein report the fermentation, isolation, structure elucidation and the biological activity of the compound.

\section{RESULTS AND DISCUSSION}

The molecular formula of 1 was determined as $\mathrm{C}_{19} \mathrm{H}_{25} \mathrm{NO}_{4}$ on the basis of the HRESIMS (found $[\mathrm{M}+\mathrm{Na}]^{+} 354.1675$, calculated for 354.1681) and NMR data, corresponding to eight degrees of unsaturation. The ${ }^{13} \mathrm{C}$ and DEPT NMR spectra displayed 19 signals for two carbonyl $\left(\delta_{\mathrm{C}} 182.0\right.$ (C-6), 195.3 (C-17)), four carbons with chemical shifts and multiplicities that agreed well with a substituted pyrrole $\left(\delta_{C} 135.1(\mathrm{C}-2), 126.6(\mathrm{C}-5), 117.5(\mathrm{C}-3), 111.0(\mathrm{C}-4)\right)$, six olefinic carbons $\left(\delta_{\mathrm{C}} 123.4(\mathrm{C}-7), 148.9\right.$ (C-8), 131.3 (C-9), 138.0
(C-10), 154.8 (C-15), 139.2 (C-16)), two aliphatic carbons bearing oxygen $\left(\delta_{C} 80.0(\mathrm{C}-11), 75.3\right.$ (C-12), two aliphatic methylene carbons $\left(\delta_{\mathrm{C}} 39.1(\mathrm{C}-13), 23.8(\mathrm{C}-14)\right)$, and three methyl groups $\left(\delta_{\mathrm{C}} 21.4(\mathrm{C}-\right.$ 18), 22.6 (C-19), 9.2 (C-20)). These observations, in combination with molecular formula, revealed that 1 possessed one ring and two $\mathrm{OH}$ groups attached to $\mathrm{C}-11$ and $\mathrm{C}-12$.

Since four of the carbons could be assigned to the pyrrole, the remaining 15 carbons were postulated to comprise a sesquiterpenoid side chain, which was further confirmed through a series of COSY and HMBC correlations (Figure 1). The cross-peaks between $\mathrm{H}-10$ and $\mathrm{H}-9 / \mathrm{H}-11$, and $\mathrm{H}-14$ and $\mathrm{H}-13 / \mathrm{H}-15$ were observed in the ${ }^{1} \mathrm{H}-{ }^{1} \mathrm{H}$ COSY spectrum. ${ }^{13} \mathrm{C}-{ }^{1} \mathrm{H}$ long-range couplings observed in the $\mathrm{HMBC}$ experiments gave the following correlations from H-20 to C-15, C-16 and C-17; H-17 to C-15 and C-16; H-13 to C-11 and C-12; H-19 to C-11, C-12 and C-13; H-18 to C-7, C-8 and $\mathrm{C}-9$; and $\mathrm{H}-9$ to $\mathrm{C}-7, \mathrm{C}-8$ and C-18. By combining all this evidence and data, we were able to assign planar structure of the fragment 2,6,10-trimethyl-6,7-dihydroxy-2,8,10-triene-undecan-1al. The characterization of the sesquiterpenoid side chain was completed by joining the C-7/C-8 olefin to the ketone carbonyl through an $\mathrm{HMBC}$ correlation from $\mathrm{H}-7$ to $\mathrm{C}-6$. A correlation was observed between $\mathrm{H}-3$ and $\mathrm{H}-7$ on the basis of the NOESY experiment, establishing the connectivity between the pyrrole and its sesquiterpene side chain.

The geometries of the C-7/C-8 and C-15/C-16 double bonds were determined to be $Z$ and $E$, respectively, on the basis of NOESY correlations of H-7 to H-18 and H-14 to H-20. The H-9/H-10 coupling constant $(J=16.0 \mathrm{~Hz})$ supported assignment of the E-geometry for the C-9/C-10 olefin. On the basis of the above evidence, the structure of compound 1 was established.

Compound 1 was biologically evaluated for in vitro cytotoxicity against three human cancer cell lines (A549, HCT-8 and Hep G2) by 
<smiles>CC(C=CC(O)C(C)(O)CCC=C(F)C=O)=CC(=O)c1ccc[nH]1</smiles>

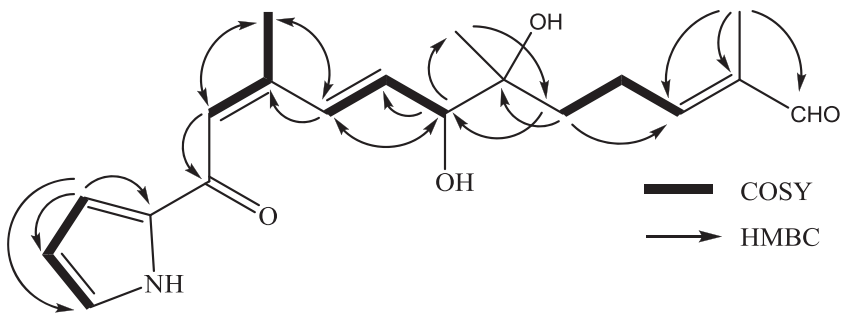

Figure 1 Key COSY and HMBC correlations for 1.

using an MTT method with camptothecin as the positive control. Compound 1 showed cytotoxic activity against the A549, HCT- 8 and Hep G2 cell lines with $\mathrm{IC}_{50}$ values of $17.6 \pm 0.004 \mu \mathrm{M}, 25.1 \pm 0.01 \mu \mathrm{M}$ and $19.4 \pm 0.003 \mu \mathrm{M}$, respectively, while the positive control exhibited $\mathrm{IC}_{50}$ values of $9.1 \pm 0.02 \mu \mathrm{M}, 8.9 \pm 0.005 \mu \mathrm{M}$ and $0.3 \pm 0.002 \mu \mathrm{M}$, respectively. In addition, compound 1 showed weak cytotoxic activity against mammalian vero cell line (normal cell, $\mathrm{IC}_{50}>\mathbf{5 0} \mu \mathrm{M}$ ). The results indicated that compound $\mathbf{1}$ has the potential as an anticancer agent.

\section{EXPERIMENTAL SECTION}

\section{General analytical procedures}

NMR experiments were performed at a $500 \mathrm{MHz}$ Bruker Avance spectrometer with TMS as internal standard. Mass spectra were recorded on a VG Auto Spec-3000 or an API QSTAR Pulsar 1 spectrometer. IR spectra were recorded on a Bruker Tensor 27 spectrometer with $\mathrm{KBr}$ pellets. Optical rotations were measured on a Horiba SEPA-300 polarimeter. Column chromatography was performed on silica gel (200-300 mesh; Qingdao Marine Chemical Co., Ltd., Qingdao, China) and Sephadex LH-20 (Amersham Biosciences, Uppsala, Sweden). TLC analysis was carried out on silica gel $\mathrm{GF}_{254}$ precoated plates $(0.20-0.25 \mathrm{~mm}$; Qingdao Marine Chemicals Co., Ltd.) with detection by heating silica gel plates sprayed with $10 \% \mathrm{H}_{2} \mathrm{SO}_{4}$ in ethanol.

\section{Biological material and cultivation}

The strain Hd7-21, isolated from the soil sample collected in DaXingAnLing virgin forest, Heilongjiang, China, was identified as Streptomyces sp. by complete $16 \mathrm{~S}$ rRNA gene sequence. This bacterium was grown on modified ISP-4 medium agar plates consisting of $1.5 \%$ agar, $1 \%$ starch, $0.1 \% \mathrm{~K}_{2} \mathrm{HPO}_{4}$, $0.1 \% \mathrm{MgSO}_{4} \bullet 7 \mathrm{H}_{2} \mathrm{O}, 0.1 \%$ Peptone, $0.05 \%$ yeast extract, $0.2 \%\left(\mathrm{NH}_{4}\right)_{2} \mathrm{SO}_{4}$, $0.2 \% \mathrm{CaCO}_{3}$ and trace element solution ( $\mathrm{pH}$ 7.0). A spore suspension and mycelium was inoculated into each of the $250 \mathrm{ml}$ Erlenmeyer flasks containing $50 \mathrm{ml}$ of liquid modified ISP-4 medium. The flasks were incubated at $28^{\circ} \mathrm{C}$ on a rotary shaker (200 r.p.m.) for 2 days. Each seed culture $(50 \mathrm{ml})$ was transferred into a $1000 \mathrm{ml}$ Erlenmeyer flask containing $200 \mathrm{ml}$ of modified ISP-4 medium. The flasks were incubated on a rotary shaker $(200$ r.p.m.) at $28^{\circ} \mathrm{C}$ for 2 weeks.

\section{Extraction and isolation}

After fermentation, the culture (201) was centrifuged to yield supernatant and a mycelial cake. The supernatant was extracted with equal volumes
Table $1{ }^{1} \mathrm{H}$ and ${ }^{13} \mathrm{C}$ NMR data for 1 in $\mathrm{CD}_{3} \mathrm{OD}$

\begin{tabular}{lll}
\hline No. & \multicolumn{1}{c}{$\delta_{H}$} & $\delta_{C}$ \\
\hline 1 & & \\
2 & & $135.1 \mathrm{~s}$ \\
3 & $6.97(\mathrm{br} \mathrm{d}, 3.7)$ & $117.5 \mathrm{~d}$ \\
4 & $6.21(\mathrm{dd}, 3.7)$ & $111.0 \mathrm{~d}$ \\
5 & $7.05(\mathrm{~m})$ & $126.6 \mathrm{~d}$ \\
6 & & $182.0 \mathrm{~s}$ \\
7 & $6.61(\mathrm{br} \mathrm{s})$ & $123.4 \mathrm{~d}$ \\
8 & & $148.9 \mathrm{~s}$ \\
9 & $7.80(\mathrm{~d}, 16.0)$ & $131.3 \mathrm{~d}$ \\
10 & $6.28(\mathrm{dd}, 16.1,6.5)$ & $138.0 \mathrm{~d}$ \\
11 & $3.99(\mathrm{~d}, 6.5)$ & $80.0 \mathrm{~d}$ \\
12 & & $75.3 \mathrm{~s}$ \\
13 & $1.67(\mathrm{~m})$ & $39.1 \mathrm{t}$ \\
& $1.54(\mathrm{~m})$ & $23.8 \mathrm{t}$ \\
14 & $2.45(\mathrm{~m})$ & $154.8 \mathrm{~d}$ \\
15 & $6.45(\mathrm{br} \mathrm{t}, 7.0)$ & $139.2 \mathrm{~s}$ \\
16 & & $195.3 \mathrm{t}$ \\
17 & $9.40(\mathrm{~s})$ & $21.4 \mathrm{t}$ \\
18 & $2.12(\mathrm{~s})$ & $22.6 \mathrm{t}$ \\
19 & $1.14(\mathrm{~s})$ & $9.2 \mathrm{t}$ \\
20 & $1.75(\mathrm{~s})$ &
\end{tabular}

Chemical shifts $(\delta)$ are in p.p.m. and $J$ in $\mathrm{Hz}$.

of ethyl acetate three times, and then samples were evaporated to dryness. The mycelial cake was extracted with 1.51 of acetone three times, and the solvent was then evaporated to dryness. The two organic extracts were finally combined to give $5.6 \mathrm{~g}$ of residue, which was subjected to column chromatography over silica gel (200-300 mesh) using gradient elution with a $\mathrm{CHCl}_{3}-\mathrm{MeOH}$ mixture (from 1:0 to 0:1) to afford fractions A-G. Fraction C was subjected to further column chromatography over silica gel, eluting with a gradient of EtOAc in petroleum ether (from $5: 1$ to $0: 1$ ), to give fractions $C_{1}-C_{5}$. Subfraction $C_{3}$ was passed over a Sephadex LH-20 column with $\mathrm{MeOH}$ as eluent and then repeatedly applied to a silica gel column eluted with $\mathrm{CHCl}_{3}-\mathrm{MeOH}$ (50:1-10:1) to yield compound 1 ( $12.8 \mathrm{mg})$.

\section{Cytotoxicity assay}

The cell growth inhibitory activities of compound $\mathbf{1}$ against the human cell lines (A549, HCT-8 and Hep G2) were determined using the previously published MTT method. ${ }^{10}$ Briefly, the cancer cell lines were cultured in RPMI 1640 medium supplemented with $10 \%$ fetal bovine serum in a humidified atmosphere of $5 \% \mathrm{CO}_{2}$ at $37^{\circ} \mathrm{C}$. Then $100 \mu \mathrm{l}$ of cell suspension was plated in 96-well plates to a final concentration of $2 \times 10^{3}$ cells per well and incubated for $12 \mathrm{~h}$. Following incubation, $50 \mu \mathrm{l}$ of the test compound solutions (in DMSO) at various concentrations was added to each well. After the exposure to compound 1 for $48 \mathrm{~h}, 50 \mu \mathrm{l}$ of MTT solution ( $1 \mathrm{mg} \mathrm{ml}^{-1}$ in phosphate-buffered saline) was added to each well, and the plates were incubated for $4 \mathrm{~h}$ at $37^{\circ} \mathrm{C}$. Then, $200 \mu \mathrm{l}$ of DMSO was added in each well. The absorbance caused by formazan crystallization was read at $550 \mathrm{~nm}$ using a microplate reader (Model 550, Bio-Rad, Hercules, CA, USA). The calculation of cell viability used the following formula: cell viability $(\%)=\left(\right.$ the average $A_{550} \mathrm{~nm}$ of the treated group/the average $A_{550} \mathrm{~nm}$ of the untreated group) $\times 100$.

(1): Colorless powder; $[\alpha]_{\mathrm{D}}^{25}+15.1\left(c 0.53, \mathrm{CH}_{3} \mathrm{OH}\right) ; \mathrm{UV}\left(\mathrm{CH}_{3} \mathrm{OH}\right) \lambda_{\max }$ $(\log \varepsilon)$ 335(14000), 290(6600) nm; IR (KBr) $v_{\max } 3400,3265,2970$, $2911,1690,1640,1610,1572,1450,1400,1310 \mathrm{~cm}^{-1} ;{ }^{1} \mathrm{H}$ and ${ }^{13}$ C NMR spectroscopic data, see Table $1 ;(+)$-ESIMS $m / z 354[\mathrm{M}+\mathrm{Na}]^{+}$; $(+)$-HRESIMS $\mathrm{m} / \mathrm{z} 354.1675[\mathrm{M}+\mathrm{Na}]^{+}$(calculated for $\mathrm{C}_{19} \mathrm{H}_{25} \mathrm{NO}_{4}$, 354.1681). 
1 Xiang, W. S., Wang, J. D., Wang, X. J. \& Zhang, J. A novel macrolide compound from Streptomyces bingchenggensis: fermentation, isolation, structure elucidation and biological properties. J. Antibiot. 62, 229-231 (2009).

2 Newman, D. J., Cragg, G. M. \& Snader, K. M. Natural products as sources of new drugs over the period 1981-2002. J. Nat. Prod. 66, 1022-1037 (2003).

3 Arasu, M. V., Duraipandiyan, V., Agastian, P. \& Ignacimuthu, S. Antimicrobial activity of Streptomyces sp. ERI-26 recovered from Western Ghats of Tamil Nadu. J. Mycol. Méd. 18, 147-153 (2008).

4 Kato, S. et al. Pyrrolostatin, a novel lipid peroxidation inhibitor from Streptomyces chrestomyceticus. Taxonomy, fermentation, isolation, structure elucidation and biological properties. J. Antibiot. 46, 892-899 (1993).

5 Macherla, V. R. et al. Glaciapyrroles A, B, and C, Pyrrolosesquiterpenes from a Streptomyces sp. isolated from an Alaskan marine sediment. J. Nat. Prod. 68, 780-783 (2005).
6 Liu, D. Z., Dong, Z. J., Wang, F. \& Liu, J. K. Two novel norsesquiterpene peroxides from basidiomycete Steccherinum ochraceum. Tetrahedron Lett. 51, 3152-3153 (2010).

7 Liu, D. Z. et al. Vibralactone: a lipase inhibitor with an unusual fused $\beta$-lactone produced by cultures of the Basidiomycete Boreostereum vibrans. Org. Lett. 25, 5749-5752 (2006).

8 Liu, D. Z., Wang, F. \& Liu, J. K. Sesquiterpenes from cultures of the Basidiomycete Conocybe siliginea. J. Nat. Prod. 70, 1503-1506 (2007).

9 Liu, D. Z., Jia, R. R., Wang, F. \& Liu, J. K. A new Spiroaxane Sesquiterpene from cultures of the Basidiomycete. Pholiota adiposa. Z. Naturforsch. 63b, 111-113 (2008).

10 Mosmann, T. Rapid colorimetric assay for cellular growth and survival: application to proliferation and cytotoxicity assays. J. Immunol. Methods 65, 55-63 (1983). 